\title{
Self-sampling to improve cervical cancer screening coverage in Switzerland: a randomised controlled trial
}

\author{
Manuela Viviano*,1, Rosa Catarino ${ }^{1}$, Emilien Jeannot ${ }^{2,3}$, Michel Boulvain ${ }^{1}$, Manuela Undurraga Malinverno ${ }^{1}$, \\ Pierre Vassilakos ${ }^{4}$ and Patrick Petignat ${ }^{1}$ \\ ${ }^{1}$ Gynecology Division, Department of Obstetrics and Gynecology, Geneva University Hospitals, Boulevard de la Cluse 30, Geneva, \\ 1205, Switzerland; ' Institute of Global Health-Faculty of Medicine, Chemin de Mines 9, Geneva 1202, Switzerland; ${ }^{3}$ School of \\ Health Sciences, University of Applied Sciences and Arts of Western Switzerland, Avenue de Champel 47, Geneva 1206, \\ Switzerland and ${ }^{4}$ Geneva Foundation for Medical Education and Research, Route de Ferney 150, Geneva 1211, Switzerland
}

Background: The aim of this study is to evaluate whether self-sampling can increase screening attendance of women who do not attend regular screening in Switzerland.

\begin{abstract}
Methods: Participants were proactively recruited in Geneva between September 2011 and November 2015. Women (25-69 years) who had not undergone CC screening in the last 3 years were considered eligible. Through a 1:1 ratio randomisation, enrolled participants were invited to either undergo liquid-based cytology, which was performed by a health-care provider (control group, CG) or to take a self-sample for HPV-testing, which was mailed to their home (intervention group, IG).
\end{abstract}

Results: A total of 331 and 336 women were randomised in the CG and in the IG, respectively. Overall, 7.3\% (95\% Cl: 4.9-10.6) women in the CG and 5.7\% (95\% Cl: 3.6-8.7) women in the IG did not undergo the initial screening $(P=0.400)$. There were $1.95 \%$ (95\% Cl: 0.8-4.3) women in the CG and 5.05\% (95\% Cl: 3.1-8.1) women in the IG with a positive screen who did not attend triage and colposcopy $(P=0.036)$.

Conclusions: The participation in CC screening in women offered self-sampling was not higher than among those offered specimen collection by a clinician. Compliance with further follow-up for women with a positive HPV test on the self-sample requires further attention.

The successful implementation of cytology-based screening has rendered cervical cancer (CC) preventable and has led to a decrease in the incidence, morbidity and mortality from this disease (Kitchener et al, 2006; Arbyn et al, 2009). Gynecologists and general physicians (GPs) in Switzerland have been promoting CC screening since the late 1960s, in this way achieving a reduction of the CC incidence by $\sim 60 \%$ (Bouchardy et al, 1990; Petignat et al, 2012). The country has an opportunistic screening system, which is essentially based on the gynecologists' and GPs' invitation for a periodic control (Petignat et al, 2012). This means that, in the absence of an organised screening program, women are only screened based on their own initiative and that of their physician (Vassilakos et al, 2015). As it is an opportunistic system, the relative statistics are difficult to monitor and the only available data come from population-based surveys conducted by the Swiss Federal Office of Public Health (FOPH) and the National Institute for Cancer Epidemiology (NICER; Petignat et al, 2012).

According to these sources, approximately $70 \%$ of eligible women have had a Pap smear in the last 3 years (Burton-Jeangros et al, 2017). The latest recommendations of the SSGO (Sociéte Suisse de Gynécologie et d'Obstétrique) propose that, in the absence of cervical abnormalities, women aged 21-29 years should be 
screened with cytology every 2 years, while women aged 30-70 years should be screened on a 3-year basis (Gerber et al, 2012). Women from lower socioeconomic groups and living in rural areas are less likely to undergo screening, which exposes them to a higher risk of developing CC (Rodriguez et al, 2005; Bischoff et al, 2009). The main obstacles to screening participation include absence of insurance coverage, low income, lack of time, and human/ emotional factors, such as lack of knowledge about CC and fear of a positive test result (Catarino et al, 2016). One of the aims of the Swiss National Cancer Control Program 2011-2015 is the implementation of a CC screening system across the nation, together with the maximisation of the screening coverage rate (National Cancer Programme for Switzerland, 2011-2015). In an effort to extend their participation rate, CC screening policies in Switzerland should take into account the main practical and emotional barriers that stand in the way of regular screening attendance, as well as the socio-demographic and cultural diversity that characterise women across the country (Bischoff et al, 2009).

When compared to cytology-based screening, Human Papillomavirus (HPV) testing has proven to be more sensitive in detecting cervical intra-epithelial neoplasia grade 2 or worse $(\mathrm{CIN} 2+)$, therefore improving the identification of women at risk for CC (Arbyn et al, 2012; Ronco et al, 2014). In addition, as it can be performed on self-collected samples (self-sampling), HPV testing has the potential to overcome some of the obstacles to conventional cytology-based screening (Arbyn et al, 2014). By avoiding the need of a clinic-based visit, HPV testing could reach women who would not otherwise attend the traditional screening program and, therefore, increase the effectiveness of CC screening (Feldman, 2014; Arbyn and Castle, 2015; Giorgi-Rossi et al, 2015).

Although several clinical trials support the use of HPV testing for primary CC screening, the use of this new strategy has to be adapted to the specific context in which it is being implemented (Verdoodt et al, 2015). Given the heterogeneity in health and screening systems, as well as in the follow-up strategies worldwide, it is crucial to determine the feasibility and population compliance with HPV-based screening in each setting (Arbyn and Castle, 2015).

We conducted a randomised controlled trial to determine (i) whether Self-sampling is a feasible and effective method to reach women who do not regularly attend CC screening with the traditional strategy in Switzerland and (ii) the proportion of women with a positive screening test that underwent the recommended follow-up clinical investigations.

\section{MATERIALS AND METHODS}

General study design. This randomised controlled clinical trial took place in Geneva between September 2011 and December 2015. Recruitment took place mainly via newspaper and web-based advertisements, as well as through flyers distributed by physicians working both at the public hospital and in private practice. A web page dedicated to the study was also created on a social network. Women from immigrant communities were also recruited in order to maximise the socio-demographic and ethnical heterogeneity of our study sample. Women interested in taking part in the study could either return a coupon in a pre-paid envelope or contact the referent medical staff via e-mail. These women were then contacted by telephone by a research nurse who checked for eligibility criteria, gave them further information and instructions regarding the study procedure and, if possible, registered them in the study. Inclusion criteria were as follows: women aged between 25 and 69 years, who had never taken part in a CC screening program or who had not undergone Pap testing in the preceding 3 years. Exclusion criteria were pregnancy or previous hysterectomy.
An online statistical software (www.randomization.com) was used to generate the randomisation list, with randomly permuted blocks of varying size (4, 6 and 8). On the basis of this list, consecutively numbered, sealed opaque envelopes containing the group allocation were prepared. When a new participant consented to participate in the study, the study nurse opened the next available envelope.

The study was approved by the Central Ethics Committee on Human Research of the Geneva University Hospitals (approval number: CER 11-034 MAT-PED 11-010). All enrolled women have given written informed consent.

Control group. Women assigned to the control group (CG) received an invitation letter to undergo liquid-based cytology testing, which was performed by a clinician. The sample for cytology was collected using the Thin Prep Pap tests (HOLOGIC, Marlborough, MA, USA). Cervical cells were collected using the Cervex-Brush Combi (Rovers, Oss, the Netherlands) as recommended by the European guidelines (Arbyn et al, 2007) and introduced into a PreservCyt solution vial. If the Pap test result showed no signs of dyskaryosis, women were invited to repeat CC screening after a 3-year interval. If cytology showed either atypical squamous cells, cannot exclude HSIL (ASC-H), or a low-grade (LSIL) or high-grade squamous intra-epithelial lesion (HSIL), women were referred to colposcopy. In case of ASC-US, triage by HPV testing was performed. The sample for HPV testing was taken directly from the PreservCyt solution vial, therefore not requiring participants to return to the clinic for an additional visit. The HPV test was performed with the Roche Cobas $4800 \mathrm{HPV}$ test (Roche Molecular Diagnostics, Pleasanton, CA, USA), which consists of a qualitative, multiplex, real-time PCR assay that provides pooled results on 12 high-risk HPV (HR-HPV) genotypes and individual results on the highest-risk genotypes, HPV 16 and HPV 18. If the HPV test was negative, women were advised to repeat CC screening after one year. If the HPV test was positive, regardless of the HPV genotype, they were referred to colposcopy.

Intervention group. Participants in the intervention group (IG) received a self-sampling kit at home. This included written instructions and drawings explaining them how to perform Selfsampling, and a sterile flocked swab that came in a transportation tube containing $1 \mathrm{ml}$ of Liquid Amies (ESwab; Copan, Brescia, Italy). Women performed Self-sampling at home and returned it by mail in a pre-paid envelope within 7 days after sample collection. The HPV test was performed with the Roche Cobas $4800 \mathrm{HPV}$ test, as described above. The test results were communicated to each participant by telephone. HPV-negative women were advised to repeat screening after 5 years. Women who tested positive for HPV-16 and/or 18 were referred to colposcopy. Participants who were positive for other HR-HPV genotypes were invited to undergo triage with Pap testing. Women with a cytological diagnosis of ASC-US or worse (ASC-US +) were referred to colposcopy, while the others were advised to repeat screening within a year.

Financial aspects. The costs associated with baseline screening were fully covered by the study for women in both groups. The costs of HPV testing triage and those of colposcopy for women in the CG were covered by the participant's insurance or by the participant herself in the absence of insurance coverage. Similarly, the costs of cytology triage and those of colposcopy for women in the IG were covered by the participants' insurance or by the participant herself in the absence of insurance coverage.

Data collection. Each participant completed a questionnaire on demographics, obstetric and gynecological history, and reasons for previous non-attendance in CC screening. The detailed results of this analysis are reported in two previously published articles (Catarino et al, 2015, 2016). 
Statistical analysis. Statistical analyses were performed using Stata IC, version 14.0 (StataCorp, College Station, TX, USA). Descriptive statistics and frequencies were analysed for all variables.

For the primary outcome, we estimated the proportion of women who did not complete baseline testing. For the secondary outcome, we estimated the proportion of participants who tested positive at either self-sampling or cytology and who did not undergo the following recommended clinical investigations to obtain a diagnosis.

We also calculated the rate of histologically-confirmed Cervical Intra-epithelial Neoplasia grade $1(\mathrm{CIN} 1)$, grade $2(\mathrm{CIN} 2)$, grade 3 $(\mathrm{CIN} 3)$ and grade 2 or worse $(\mathrm{CIN} 2+)$.

Differences between mean values were assessed using the T-Student test, whereas differences between percentages were tested with the Pearson $\mathrm{X}^{2}$-test.

Results were considered statistically significant at $P \leqslant 0.05$.

The sample size was set to 550 women in each group and was calculated to be able to detect a $10 \%$ difference in the response rate between the IG (60\%) and the CG (50\%) with a power of $90 \%$ and a $95 \%$ confidence level.

\section{RESULTS}

Sample characteristics. The baseline characteristics of women in the two groups were similar (see Table 1). The mean and s.d. of the age of the participants were 42.0 (10.8) years and 42.3 (10.9) years in the CG and IG, respectively. The majority of women in the two groups had previously undergone CC screening, with the last screening test dating back to at least four years $(80.8 \%$ and $82.4 \%$ in the CG and in the IG, respectively). A high proportion of women in both groups were Latin American (31.7\% and 31.3\% in the CG and in the IG, respectively) and $42.3 \%$ of women in the CG and $35.8 \%$ of women in the IG did not have a health insurance.

Main study results. A total of 941 women were assessed for eligibility; of these, 667 (70.9\%) fulfilled the eligibility criteria and were enrolled in the study (see Figure 1).

Following randomisation, 331 women were assigned to the CG and were thus invited for a clinician-performed liquid-based cytology testing. Among these, 307 (92.7\%) participants attended at a clinic-based Pap testing. There were $252(82.1 \%)$ women with a normal cytology and 55 (17.9\%) women with ASC-US or worse. Out of the 55 women (17.9\%) with an ASC-US + result, 23 (41.8\%) had an ASC-H + cytology result and were referred to colposcopy. The cytology samples of the 32 women (58.2\%) with an ASC-US diagnosis were processed for HPV testing. Among these, 7 (25.0\%) women were HPV-positive and were also referred to colposcopy for further evaluation.

Three-hundred and thirty-six women were randomised in the IG and were thus invited to perform Self-sampling. Of these women, 317 (94.3\%) participants performed and returned their self-sample. Overall, 242 (76.3\%) women were HPV-negative, and 75 (23.7\%) were HPV-positive. Among the 75 (72.0\%) women who tested positive for HPV, 21 (28.0\%) were positive for HPV-16 and/ or HPV-18 and were referred directly to colposcopy. Fifty-four women $(72.0 \%)$ were positive to other HR-HPV types and therefore underwent triage by cytology. Six women positive for other HR-HPV types did not undergo Pap testing. Among the participants who underwent cytology triage, 15 of them (34.9\%) were ASC-US + and were therefore addressed to colposcopy. Women positive at HPV testing with a negative cytology were recalled for repeat HPV testing at 1 year.

Primary and secondary outcomes. Overall, 24/331 (7.3\%, 95\% CI: 4.9-10.6) women in the CG and 19/336 (5.6\%, 95\% CI: 3.6-8.7) women in the IG did not attend the initial screening $(P=0.400)$. A total of $6 / 307(1.95 \%, 95 \%$ CI: $0.8-4.3)$ women in the CG and
Table 1. Demographic characteristics of the study

participants

\begin{tabular}{|c|c|c|c|c|}
\hline & \multicolumn{2}{|c|}{$\begin{array}{l}\text { Control group } \\
\quad(n=331)\end{array}$} & \multicolumn{2}{|c|}{$\begin{array}{l}\text { Intervention, group } \\
\qquad(n=336)\end{array}$} \\
\hline Age, mean \pm s.d. & & & & \\
\hline $\begin{array}{l}\text { Previous CC screening } \\
\text { Yes, } n(\%) \\
\text { No }\end{array}$ & $\begin{array}{r}268 \\
63\end{array}$ & $\begin{array}{l}81.0 \\
19.0\end{array}$ & $\begin{array}{r}277 \\
59\end{array}$ & $\begin{array}{l}82.4 \\
17.6\end{array}$ \\
\hline $\begin{array}{l}\text { Relationship status } \\
\text { With a partner } \\
\text { Single }\end{array}$ & $\begin{array}{l}154 \\
177\end{array}$ & $\begin{array}{l}46.5 \\
53.5\end{array}$ & $\begin{array}{l}161 \\
175\end{array}$ & $\begin{array}{l}47.9 \\
52.1\end{array}$ \\
\hline $\begin{array}{l}\text { Nationality } \\
\text { Swiss } \\
\text { Other European } \\
\text { Asian } \\
\text { African } \\
\text { Latin American } \\
\text { Other }\end{array}$ & $\begin{array}{r}47 \\
58 \\
61 \\
33 \\
106 \\
26\end{array}$ & \begin{tabular}{l|}
14.2 \\
17.5 \\
18.4 \\
10 \\
32.0 \\
7.9
\end{tabular} & $\begin{array}{r}47 \\
66 \\
45 \\
30 \\
105 \\
40\end{array}$ & $\begin{array}{l}14 \\
19.6 \\
13.4 \\
8.9 \\
31.3 \\
12.1\end{array}$ \\
\hline $\begin{array}{l}\text { Religion } \\
\text { Christians } \\
\text { Muslims } \\
\text { Other } \\
\text { Atheists } \\
\text { Unknown }\end{array}$ & $\begin{array}{r}158 \\
21 \\
92 \\
59 \\
1\end{array}$ & $\begin{array}{r}47.7 \\
6.3 \\
28.1 \\
17.8 \\
0.3\end{array}$ & $\begin{array}{r}157 \\
24 \\
75 \\
77 \\
3\end{array}$ & $\begin{array}{r}46.7 \\
7.1 \\
22.3 \\
22.9 \\
0.9\end{array}$ \\
\hline $\begin{array}{l}\text { Number of children, } \\
\text { mean } \pm \text { s.d. }\end{array}$ & & & & \\
\hline $\begin{array}{l}\text { Education } \\
\text { Apprenticeship/high school } \\
\text { University } \\
\text { None }\end{array}$ & $\begin{array}{r}150 \\
176 \\
5\end{array}$ & $\begin{array}{r}45.3 \\
53.2 \\
1.5\end{array}$ & $\begin{array}{r}169 \\
159 \\
3\end{array}$ & $\begin{array}{r}50.3 \\
47.3 \\
0.9\end{array}$ \\
\hline $\begin{array}{l}\text { Employment status } \\
\text { Unemployed } \\
\text { Employed part or full time } \\
\text { Retired } \\
\text { Student }\end{array}$ & $\begin{array}{r}58 \\
242 \\
7 \\
12\end{array}$ & $\begin{array}{r}17.5 \\
73.1 \\
2.1 \\
3.6\end{array}$ & $\begin{array}{r}60 \\
253 \\
8 \\
10\end{array}$ & $\begin{array}{l}18 \\
76 \\
2.4 \\
3\end{array}$ \\
\hline $\begin{array}{l}\text { Insurance } \\
\text { Yes } \\
\text { No }\end{array}$ & $\begin{array}{l}192 \\
139\end{array}$ & $\begin{array}{l}58.0 \\
42.0\end{array}$ & $\begin{array}{l}215 \\
120\end{array}$ & $\begin{array}{l}64.2 \\
35.8\end{array}$ \\
\hline
\end{tabular}

Abbreviations: $\mathrm{CC}=$ cervical cancer; HPV $=$ Human Papillomavirus; $n=$ number.

16/317 (5.05\%, 95\% CI: $3.1-8.1)$ women in the IG with a positive screening test were lost between baseline screening and colposcopy $(P=0.036)$. The overall proportion of women who missed either the initial screening or the follow-up was 30/331 (9.1\%; 95\% CI: 6.4-12.7) participants in the CG and 35/336 (10.4\%, 95\% CI: 7.6-14.2) participants in the IG $(P=0.650$; See Table 2$)$.

Among these women, $10 / 30$ (33.3\%, 95\% CI: 19.1-51.3) and 13/35 (37.1\%, 95\% CI: 23.1-53.7) did not have a health insurance in the CG and in the IG, respectively $(P=0.87)$. Overall, $22 / 30$ (73.3\%, 95\% CI: 55.4-86.0) and 25/35 (71.4\%, 95\% CI: 54.8-83.8) of women who exited the study had a part or full-time job in the CG and in the IG, respectively $(P=0.84)$. Among women who dropped out between baseline screening and colposcopy in the IG, 12/17 (70.6\%, 95\% CI: 46.6-87.0) of them had part- or full-time job.

Histological diagnoses. A total of 25 women underwent colposcopy in the CG. The detection rate of CIN2 + in this group was 4/ 331 (1.3\%, 95\% CI: $0.4-3.2)$. All of these women had CIN grade 3 (CIN3).

Thirty women underwent colposcopy in the IG. The CIN2 + detection rate was 10/336 (3.0\%, 95\% CI: 1.6-5.5); of these, 6 women had a CIN3 and 4 had a CIN3 (Table 3).

The difference between the detection rate of CIN2 + in the CG $(1.2 \%)$ and in the IG (3.0\%) was not statistically significant $(P=0.110)$. 


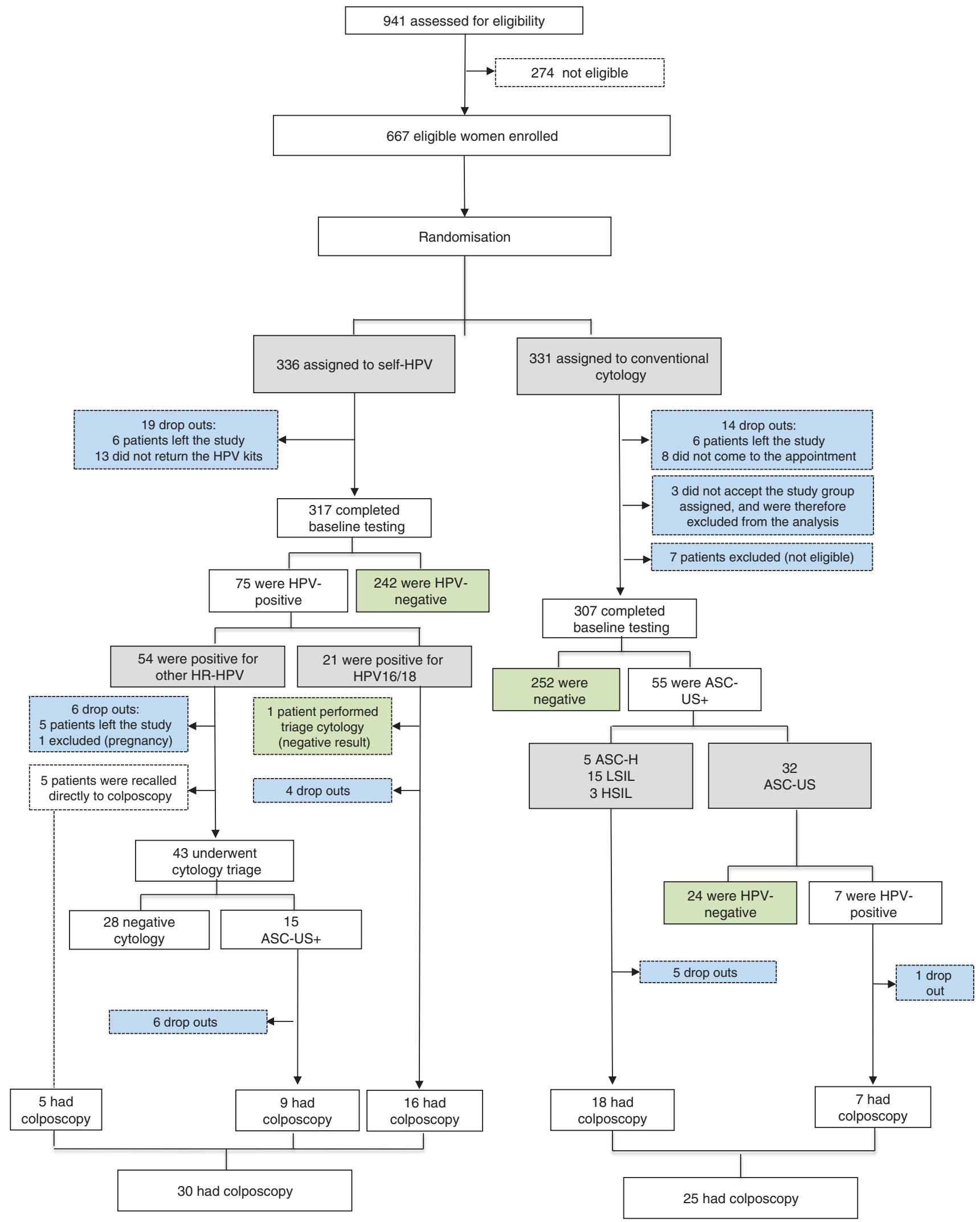

Figure 1. Study flowchart. HPV = Human Papillomavirus; ASC-US = Atypical squamous cells of undetermined significance; $A S C$-US $+=$ Atypical squamous cells of undetermined significance or worse; ASC-H = Atypical squamous cells of undetermined significance cannot exclude HSIL; $\mathrm{L}-\mathrm{SIL}=$ Low-grade squamous intra-epithelial lesion; HSIL = High-grade squamous intra-epithelial lesion. 
Table 2. Participants who exited the study

\begin{tabular}{|l|c|c|c|}
\hline & $\begin{array}{c}\text { Control } \\
\text { group } \\
\mathbf{N}(\%)\end{array}$ & $\begin{array}{c}\text { Intervention } \\
\text { group } \\
\mathbf{N}(\%)\end{array}$ & $\boldsymbol{P}$ \\
\hline Baseline screening & $24 / 331(7.1)$ & $19 / 336(5.6)$ & 0.400 \\
\hline $\begin{array}{l}\text { Between baseline } \\
\text { screening and colposcopy }\end{array}$ & $6 / 307(1.95)$ & $16 / 317(5.05)$ & 0.036 \\
\hline Overall & $30 / 331(9.1)$ & $35 / 336(10.4)$ & 0.650 \\
\hline
\end{tabular}

\section{DISCUSSION}

Our results show that Self-sampling does not improve screening uptake among non- and under-screened women willing to participate in a study on CC screening in Switzerland. Clinicbased Pap testing and home-performed Self-sampling achieved a comparable initial attendance. In contrast with our results, other studies found that inviting women to perform Self-sampling by mailing them the HPV kit directly at home results in a greater participation when compared to that obtained with an invitation letter for a clinic-based Pap test (Huynh et al, 2010; Penaranda et al, 2015; Sultana et al, 2016). The recruitment strategy, could partly explain the difference between our findings and those of other trials. While our study population of non- and underscreened women was proactively recruited through advertisements, the participants in other trials, such as the iPap in Australia, were selected directly through the national register (Sultana et al, 2016). Therefore, women included in our study were possibly more willing to attend CC screening, regardless of the method. A systematic review and meta-analysis reported that the overall participation was similar for self- and clinicianperformed cervical sampling when women had to 'opt-in' screening, as in our trial (Verdoodt et al, 2015). Women in the CG with a positive screening test went directly to colposcopy, resulting in a lower drop-out rate compared to that of participants in the IG, who had to undergo clinic-based cytology triage. The significant difference between these two proportions suggests a certain reluctance to undergo further clinic-based investigations when a screening test is positive. It is worth mentioning that about half of the women in the two groups did not have a health insurance. This means that while the possibility to benefit of a free primary screening service may have contributed to their recruitment, the fact that the costs of the clinical management that followed a positive screening test were at their charge may have discouraged them from undergoing further clinical management. Considering that one of the main obstacles to screening participation is its cost, this aspect may have influenced the higher loss to follow-up rate in the IG, where an additional clinical step was required (Loerzel and Bushy, 2005; Catarino et al, 2015). Furthermore, as another barrier to screening attendance is lack of time, the time-consuming aspect of an additional clinical visit may explain the higher dropout rate in the IG (Catarino et al, 2016). This concept is reinforced by the finding that the majority of participants who dropped out between the baseline screening results and colposcopy were working women, who may have lacked the time to undergo multiple clinical visits.

We found that HPV testing for CC screening led to an increased detection of CIN2 + lesions in the IG when compared to the CG. Although in our case they are compatible with a random fluctuation, these results are in line with previous studies conducted in other industrialised countries (Cuzick et al, 2006; Bulkmans et al, 2007; Naucler et al, 2007; Ronco et al, 2010; Rijkaart et al, 2012; Ronco et al, 2014), which support the use of $\mathrm{HPV}$ testing as a primary screening tool. A meta-analysis on the
Table 3. Histological diagnoses' distribution in the two study groups

\begin{tabular}{|l|c|c|c|}
\hline & Control group (n) \% & $\begin{array}{c}\text { Intervention group } \\
\%(\boldsymbol{n})\end{array}$ & $\boldsymbol{P}$ \\
\hline $\mathrm{CIN} 1$ & $2.4 \%(8 / 331)$ & $0.3 \%(1 / 336)$ & 0.17 \\
\hline $\mathrm{CIN} 2$ & $0(0 \%)$ & $1.2 \%(4 / 336)$ & 0.54 \\
\hline $\mathrm{CIN} 3$ & $1.2 \%(4 / 331)$ & $1.8 \%(6 / 336)$ & 0.11 \\
\hline $\mathrm{CIN} 2+$ & $1.2 \%(4 / 331)$ & $3.0 \%(10 / 336)$ & \\
\hline $\begin{array}{l}\text { Abbreviations: CIN1 = cervical intraepithelial neoplasia grade 1; CIN2 }=\text { cervical intrae- } \\
\text { pithelial neoplasia grade 2; CIN3=cervical intraepithelial neoplasia grade 3; CIN2 }+= \\
\text { cervical intraepithelial neoplasia grade 2 or more severe; } n=\text { number. }\end{array}$ \\
\hline \multicolumn{4}{|l}{}
\end{tabular}

subject suggests that, when PCR-based assays that amplify DNA viral sequences are used, the performance of HPV testing on clinician-collected samples is comparable to that of Selfsampling (Arbyn et al, 2014). Although recent results from a qualitative study conducted in Switzerland have shown a certain degree of skepticism toward the Self-sampling test, the majority of women in favor of this technique were the unscreened ones (Fargnoli et al, 2015). Furthermore, the absence of invalid HPV test results supports the simplicity and feasibility of this technique when performed by women themselves, outside the clinical setting.

One of the main problems of opportunistic screening systems, such as the one in Switzerland, is that they can easily miss people who have limited access to information and health services, thus not adequately covering the entire targeted population (Bischoff et al, 2009). The first step in building a strong screening service in Switzerland should be the implementation of a coordinating service in each Canton, with the aim of establishing a screening program in order to inform and raise the population's level of awareness of CC and its prevention. In addition, in order to increase the program's effectiveness, the cost of primary screening should be covered by federal funds, at least for women whose annual income does not exceed a certain threshold. Further studies are needed in order to validate the proactive screening strategy $v s$ the opportunistic one in Switzerland.

One promising way to increase follow-up compliance would be by incorporating HPV testing in a 'screen-and-treat' strategy, which would simplify the clinical management that follows a positive test result. By reducing the number of clinical visits, the 'screen-and-treat' strategy may be preferable in developing countries, where some of the main factors influencing the success of CC screening campaigns are low patient compliance and loss to follow-up. The more promising option for industrialised countries such as Switzerland appears to be the one which, by reducing the number of clinical visits while alleviating the costs of CC screening, would allow to break down the main barriers to CC screening attendance.

Strengths and limitations. One strength of this study was the participation of ethnically diverse women, which reflects the reallife population in the Swiss canton of Geneva. Another strength is represented by the fact that we used a real-time PCR that allowed distinguishing the HPV-16/18 genotypes, which are associated to a higher risk of developing CC, from other $12 \mathrm{HR}-\mathrm{HPV}$ types. In addition, as opposed to other trials using Self-sampling, which registered between 0.5 and $0.7 \%$ of unsatisfactory HPV test results, we had no invalid results (Bosgraaf et al, 2015; Giorgi-Rossi et al, 2015).

Our study has some limitations that need to be addressed. We were able to recruit fewer participants than expected by the sample size estimation. The assumptions used to estimated the sample size 
were different from the actual recruitment process of the trial, thus limiting the power to obtain statistically significant difference between the two options for initial screening. In addition, our study was conducted in an urban setting, which limits the generalisation of our results to the population living in Switzerland. Another reason for which the study group was not entirely representative of the population living in Geneva and its surroundings is the proportion of women with previous CC screening, which was rather high as compared with the lower rates in Geneva and its surroundings. Additionally, an important preselection bias is likely to have occurred. Since we selected women who had actively responded to the campaign's advertisements, participants were possibly more willing to accept any CC screening approach than the general population.

\section{CONCLUSION}

When compared to Pap testing, Self-sampling does not increase screening participation for non- and under-screened women who are motivated to participate in a CC screening campaign in Switzerland. The clinical management of HPV-positive women requires further attention in order to define the most acceptable algorithm in terms of women compliance, financial and clinical aspects.

\section{ACKNOWLEDGEMENTS}

This study was supported by the Oncosuisse/Krebsforschung Schweiz (Grant KFS 02691-08-2010). The funders had no role in study design, data collection and analysis, decision to publish, or preparation of the manuscript. The trial was registered on ClinicalTrials.gov (NCT02698423).

\section{CONFLICT OF INTEREST}

The authors declare no conflict of interest.

\section{REFERENCES}

Arbyn M, Reboli M, De Kok IM, Fender M, Becker N, O’Reilly M, Andrae B (2009) The challenges of organising cervical screening programmes in the 15 old member states of the European Union. Eur J Cancer 45: 2671-2678.

Arbyn M, Castle PE (2015) Offering self-sampling kits for HPV testing to reach women who do not attend in the regular cervical cancer screening program. Cancer Epidemiol Biomarkers Prev 24: 769-772.

Arbyn M, Herbert A, Schenck U, Nieminen P, Jordan J, Mcgoogan E, Patnick J, Bergeron C, Baldauf JJ, Klinkhamer P, Bulten J, Martin-Hirsch P (2007) European guidelines for quality assurance in cervical cancer screening: recommendations for collecting samples for conventional and liquidbased cytology. Cytopathology 18: 133-139.

Arbyn M, Ronco G, Anttila A, Meijer CJ, Poljak M, Ogilvie G, Koliopoulos G, Naucler P, Sankaranarayanan R, Peto J (2012) Evidence regarding HPV testing in secondary prevention of cervical cancer. Vaccine 30(Suppl 5): F88-F99.

Arbyn M, Verdoot F, Snijders PJ, Verhoef VM, Suonio E, Dillner L, Minozzi S, Bellisario C, Banzi R, Zhao FH, Hillemanns P, Anttila A (2014) Accuracy of human papillomavirus testing on self-collected versus cliniciancollected samples: a meta-analysis. Lancet Oncol 15: 172-183.

Bischoff A, Greuter U, Fontana M, Wanner P (2009) Cervical cancer screening among immigrants in Switzerland. Divers Health Care 6: 159-169.

Bosgraaf RP, Verhoef VM, Massuger LF, Siebers AG, Bulten J, de Kuyper-deRidder GM, Meijer CJ, Snijders PJ, Heideman DA, IntHout J, van Kemenade FJ, Melchers WJ, Bekkers RL (2015) Comparative performance of novel self-sampling methods in detecting high-risk human papillomavirus in 30,130 women not attending cervical screening. Int J Cancer 136: 646-655.

Bouchardy C, Fioretta G, Raymond L, Vassilakos P (1990) Age differentials in trends of uterine cervical cancer incidence from 1970 to 1987 in Geneva. Rev Epidemiol Sante Publique 38: 261-262.

Bulkmans NWJ, Berkhof J, Rozendaal L, van Kemenade FJ, Boeke AJ, Bulk S, Voorhorst FJ, Verheijen RH, van Groningen K, Boon ME, Ruitinga W, van Ballegooijen M, Snijders PJ, Meijer CJ (2007) Human Papillomavirus DNA testing for the detection of cervical intraepithelial neoplasia grade 3 and cancer: 5-year follow-up of a randomised controlled implementation trial. Lancet 370: 1764-1772.

Burton-Jeangros C, Cullati S, Manor O, Courvoisier DS, Bouchardy C, Guessous I (2017) Cervical cancer screening in Switzerland: crosssectional trends (1992-2012) in social inequalities. Eur J Public Health 27(1): 167-173.

Catarino R, Vassilakos P, Stadali-Ullrich H, Royannez-Drevard I, Guillot C, Petignat P (2015) Feasibility of at-home self-sampling for HPV testing as an appropriate screening strategy for nonparticipants in Switzerland: preliminary results of the DEPIST study. J Low Genit Tract Dis 19: 27-34.

Catarino R, Vassilakos P, Royannez-Drevard I, Guillot C, Alzuphar S, Fehlmann A, Meyer-Hamme U, Petignat P (2016) Barriers to Cervical Cancer Screening in Geneva (DEPIST Study). J Low Genit Tract Dis 20: $135-138$.

Cuzick J, Clavel C, Petry KU, Meijer CJ, Hoyer H, Ratnam S, Szarewski A, Birembaut P, Kulasingam S, Sasieni P, Iftner T (2006) Overview of the European and North American studies on HPV testing in primary cervical cancer screening. Int J Cancer 119: 1095-1101.

Fargnoli V, Petignat P, Burton-Jeangros C (2015) To what extent will women accept self-sampling for cervical cancer screening? A qualitative study conducted in Switzerland. Int J Womens Health 7: 883-888.

Feldman S (2014) Human papillomavirus testing for primary cervical cancer screening: is it time to abandon Papanicolau testing? JAMA Intern Med 174: $1539-1540$.

Gerber S, Heinzl S, Canonica C, Fehr M, Frey Tirri B, Mueller M, Obwegeser J, Seydoux J, Wight E (2012) Mise à jour du dépistage du cancer du col et du suivi en colposcopie. Avis d'expert No 40. Bern, Switzerland.

Giorgi-Rossi P, Arbyn M, Meijer CJ (2015) Cervical cancer screening by human papillomavirus testing followed by cytology triage. JAMA Intern Med 175: 1068 .

Huynh J, Howard M, Lytwyn A (2010) Self-collection for vaginal human papillomavirus testing: systematic review of studies asking women their perceptions. J Low Genit Tract Dis 14: 356-362.

Kitchener HC, Castle PE, Cox JT (2006) Achievements and limitations of cervical cytology screening. Vaccine 24(suppl 3): S63-S70.

Loerzel VW, Bushy A (2005) Interventions that address cancer health disparities in women. Fam Community Health 28: 79-89.

Naucler P, Walter R, Törnberg S, Strand A, Wadeli G, Elfgren K, Radberg T, Strander B, Johansson B, Forslund O, Hansson B-G, Rylander E, Dillner J (2007) Human papillomavirus and papanicolau tests to screen for cervical cancer. N Engl J Med 357: 1589-1597.

National Cancer Programme for Switzerland (2011-2015) Communication NCP. Bern January 2011: Oncosuisse.

Penaranda E, Molokwu J, Flores S, Byrd T, Brown L, Shokar N (2015) Women's attitudes toward cervicovaginal self-sampling for high-risk HPV infection on the US-Mexico border. J Low Genit Tract Dis 19: 323-328.

Petignat P, Untiet S, Vassilakos P (2012) How to improve cervical cancer screening in Switzerland? Swiss Med Wkly 142: w13663.

Rijkaart DC, Berkhof J, Rozendaal L, van Kemenade FJ, Bulkmans NW, Heideman DA, Kenter GG, Cuzick J, Snijders PJ, Meijer CJ (2012) Human papillomavirus testing for the detection of high-grade cervical intraepithelial neoplasia and cancer: final results of the POBASCAM randomised controlled trial. Lancet Oncol 13: 78-88.

Rodriguez A, Ward LM, Pérez-Stable EJ (2005) Breast and cervical cancer screening: impact of health insurance status, ethnicity, and nativity of latinas. Ann Fam Med 3: 235-241.

Ronco G, Dillner J, Elfström KM, TUnesi S, Snijders PJ, Arbyn M, Kitchener H, Segnan N, Gilham C, Giorgi-Rossi P, Berkhof J, Peto J, Meijer CJ, International HPV screening working group (2014) Efficacy of HPV-based screeningfor prevention of invasive cervical cancer: follow-up of four European randomised controlled trials. Lancet 383: 524-532.

Ronco G, Giorgi-Rossi P, Carozzi F, Confortini M, Dalla Palma P, Del Mistro A, Ghiringhello B, Girlando S, Gillio-Tos A, De Marco L, 
Naldoni C, Pierotti P, Rizzolo R, Schincaglia P, Zorzi M, Zappa M, Segnan N, Cuzick J, New Technologies for Cervical Cancer screening (NTCC) working group (2010) Efficacy of human papillomavirus testing for the detection of invasive cervical cancers and cervical intraepithelial neoplasia: a randomised controlled trial. Lancet Oncol 11: 249-257.

Sultana F, English DR, Simpson JA, Drennan KT, Mullins R, Brotherton JM, Wrede CD, Heley S, Saville M, Gertig DM (2016) Home-based HPV self-sampling improves participation by never-screened and underscreened women: results from a large randomised trial (iPap) in Australia. Int J Cancer 139: 281-290.

Vassilakos P, Catarino R, Frey Tirri B, Petignat P (2015) Cervical cancer screening in Switzerland: time to rethink the guidelines. Swiss Med Wkly 145: w14112.
Verdoodt F, Jentschke M, Hillemanns P, Racey CS, Snijders PJ, Arbyn M (2015) Reaching women who do not participate in the regular cervical cancer screening programme by offering self-sampling kits: a systematic review and meta-analysis of randomised trials. Eur J Cancer 51: $2375-2385$.

(c) (i) (2) (2) This work is licensed under the Creative Commons (c) Attribution-Non-Commercial-Share Alike 4.0 International License. To view a copy of this license, visit http:// creativecommons.org/licenses/by-nc-sa/4.0/

(C) The Author(s) named above 2017 